\title{
Report 非
}

DOE-ER-10550-2

Tit1e: CCNY Collaboration with BNL in R\&D for ISABELLE Detectors

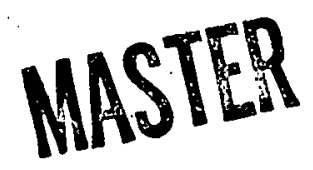

Technical Progress Report for the period November 1, 1980 to June 10, 1981

by S.J. Lindenbaum (Principal Investigator)

Physics Department

City College of New York

acting through the Research Foundation of the City University of New York

138th Street and Convent Avenue

New York, New York 10031

Contract \# DE-ACO2-79ER-10550

This report was prepared as an account of work sponsored by the U.S. Government. Neither the U.S. or the D.O.E. nor any of their employees, nor any of their contractors, subcontractors, or their employees makes any warrantee express or implied or assumes any legal liability or responsibility for the accuracy, completeness or usefulness of any information, apparatus, product or process disclosed or represents that its use would not infringe privately owned rights.

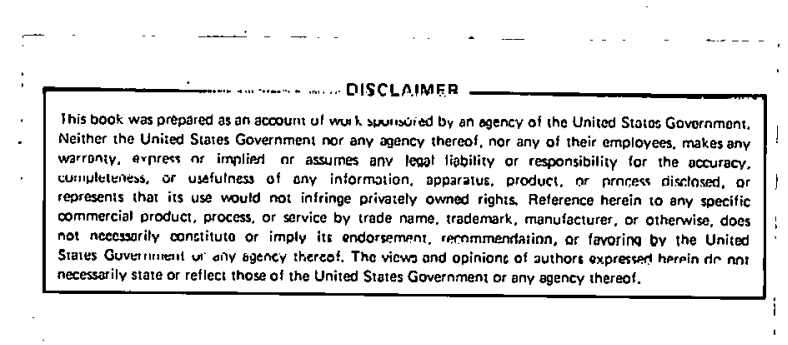

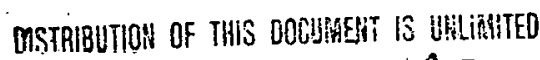




\section{DISCLAIMER}

This report was prepared as an account of work sponsored by an agency of the United States Government. Neither the United States Government nor any agency Thereof, nor any of their employees, makes any warranty, express or implied, or assumes any legal liability or responsibility for the accuracy, completeness, or usefulness of any information, apparatus, product, or process disclosed, or represents that its use would not infringe privately owned rights. Reference herein to any specific commercial product, process, or service by trade name, trademark, manufacturer, or otherwise does not necessarily constitute or imply its endorsement, recommendation, or favoring by the United States Government or any agency thereof. The views and opinions of authors expressed herein do not necessarily state or reflect those of the United States Government or any agency thereof. 


\section{DISCLAIMER}

Portions of this document may be illegible in electronic image products. Images are produced from the best available original document. 
The difference in ionization loss of particles as a function of their velocity is widely used as a technique to identify the particles.

We have studied the ionization loss in gas samples an order of magnitúde smaller than previously investigated. In order to do this we have developed and employed new techniques which use a longitudinal drift ionization detector and fast analog to digital conversion techniques which allow us to effectively slice a piece of track into very small samples by electronic means using a small prototype chamber. We have demonstrated that this technique can substantially improve the mass resolution capability of gas particle detectors. We have also shown that only a rather coarse analog to digital converter $(A D C)$ resolution is required to capture all the information needed with the truncated mean sampling method we employ to determine the relative energy loss.

Thus: we conclude these new developments can substantially increase the sensitivity of particle separation by ionization measurements via gar. particle detectors.

We are now testing a larger ten-layer prototype which will allow us to optimize the design for a large type of test chamber which could then be utilized to design actual experimental measuring equipment. 
The difference in ionization loss of particles as a function of their velocity is widely used as a technique to identify the particles.

No 9 have studied the ionization loss in gas samples an order of magnitude smaller than previcusly investigated. In order to do this $\hat{\jmath}^{-2}$ have developed and loyed new techniques $\wedge$ which use a longitudinal

drift ionization detector and fast analog to digital conversion techniques one

which allow ${ }^{\text {at3 }}$ to effectively slice a piece of track into very small samples by electronic means using a small prototype chamber. It was demonstrated that this technique can substantially improve the mass resolution capability of gas particle detectors, and was to digital converter (ADC) resolution is required to capture all the information needed with the truncated mean sampling method $\operatorname{employ~}^{e d}$ to determine the relative energy loss.

No 4 Tho condere these new developments can substantially increast the sensitivity of particle separation by ionization measurements via gas particle detectors.

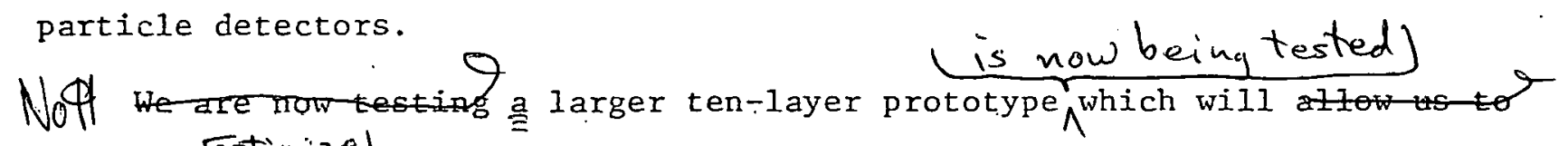
optime for a large type of test chamber which could then be utilized to design actual experimental measuring equipment. 
I. The analysis of the test run in the summer of 1980 was completed remored (pub.lit.)

and published in the Reference attached. The results established that with the small one-layer test chamber, that we had employed our new method of small electronic sampling of tracks in a longitudinal drift chamber increased the sensitivity for particle identification by a factor of about two.

II. During this year we have, with the additional collaboration of a Univeristy of Lund group constructed a ten-layer prototype chamber 4". wide by $10^{\prime \prime}$ high with $40 \mathrm{~cm}$ of gas path along the beam. The purpose of this chamber was to allow us to apply the technique to a multi-layer model chamber which is a prototype of a large chamber for spectrometer experimental use.

We developed and built ultra fast analog to digital converters (ADC's) to enable us to sample the drift chamber pulse shapes in $10 \mathrm{~ns}$ intervals corresponding to about $1 / 2 \mathrm{~mm}$ of track length.

We have run a shakedown test at $\mathrm{BNL}$ in a $3.5 \mathrm{GeV} / \mathrm{c}$ test beams. The results of this test indicate that our ten-layer chamber results are consistent within the experimental errors with our expectations.

A critical test of this ten-layer chamber is planned thls summer using ä test beam at CERN (the BNL test beam will not be available again till next April). This test should provide us with the necessary information to optimize the design for the large ten-layer module we plan to build as a demonstration of a practical type device using these new techniques.

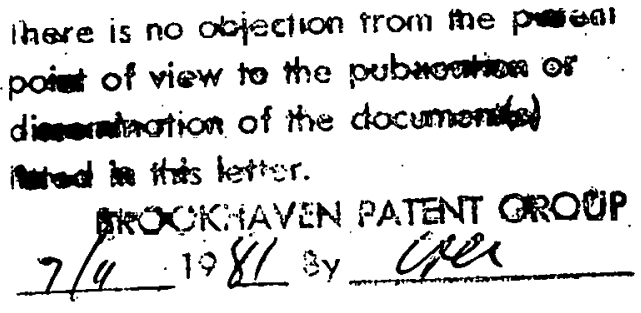


The work done under this contract falls within the scope and is in compliance with the agreement.

The Principal Investigator devoted approximately $15 \%$ of his time for 12 months.

\section{TECHNICAL REPORTS}

T. Ludlam, E.D. Platner, V.A. Polychronakos, S.J. I.indenbaum, M.A. Kramer, and Y. Teramoto. "Relativistic Rise Measurements with Very Fine Sampling Intervals". IEEE Transactions on Nuclear Science Vol. NS-28, No. 1, 439(1981).

T. Ludlam, E.D. Platner, V.A. Polychronakos, S.J. Lindenbaum, M.A. Kramer, Y. Teramoto, T. Akesson and G. Jarlskog. "Prototype Particle Identifier Using Multiple Layers of Gas and the Fine Sampling Method". Paper submitted to 1981 Nuclear Science Symposium, October 21-23, 1981, San Francisco, California. 